\title{
PREPARATORY STAGES OF PSEUDOHAZIS SHASTAENSIS BEHRENS.
}

\author{
BY HARRISON G. DYAR, NEW YORK.
}

Pseudohazis shastaensis Behrens.* 1880-Behrens, No. Am. ent., i, 62. var. DenUdata Neumoegen.

I89I-Neum., Can. ent., xviii, I45.

I have received the eggs of this species from Mrs. S. J. Kidder, who has very kindly taken the trouble to find them and forward them to me in good condition. They were received in the fall of 1892 and hatched on May II th following.

E ggs. -Deposited in a ring shaped mass around a leaf stem or twig, without covering. Oval, flattened at the sides, round on the base, but flat on top, forming a distinct, elliptical area, slightly depressed centrally at the micropyle. Smooth, shining, pale brown, covered with a white pigment below and on the narrower sides and forming a distinct ring around the top surface, inside of which is a dark brown border. Height $\mathrm{t} .8 \mathrm{~mm}$.; broad diameter centrally r. $6 \mathrm{~mm}$., at top I.I $\mathrm{mm}$.; narrow diameter centrally $0.8 \mathrm{~mm}$., at top $0.7 \mathrm{~mm}$. Duration of this stage throughout the hibernating period.

Larva, stage I.-Head round, bilobed, shining black; antennae prominent; width $0.7-0.75 \mathrm{~mm}$. Body dull black, feet reddish. Rows of modified processes, apparently arranged as in the mature larva, but only three rows discernible. Row i very long, rather slender, the anterior ones distinctly furcate or trifid, each branch with a very long, minutely spinulose, pale seta, even longer than the shaft. The processes are

* The common form of Pseudohazis with purplish fore wings has, strictly, never been described. Bois. duval says of eglanterina "alae anticae albido-carneae" which applies to the form described as arizonensis by Strecker. Behrens' shastaensis was described from very black examples of the purple winged form, so this name will obtain. The form is constant, and has as good right to specific recognition as any species in the genus. shorter posteriorly, not furcate, though many bear two of the long setae. Row ii shorter than $\mathrm{i}$ with a seta from the middle and one from apex. Row iii very short, but many of the tubercles bear two setae. Anal plate concolorous with anal feet. Duration of this stage 13 days.

Stage II.-Head shining black, labrum and bases of antennae paler; width r.O-r.2 $\mathrm{mm}$. Body black, the tips of the spines straw colored. Processes very long, especially on joints 2-4 dorsally, where they are I.5 mm. long. The others are nearly as long, but become gradually shorter posteriorly. The processes bear about six branches and are furcate at tip, each branch bearing a single pale stiff hair, longer than the branch itself. The branches arise alternately. Anal plates three, large, black; one suranal, the others at base of each anal foot.

Stage $I I I$.-Head depressed medially, shining black, clypeus whitish; width I.4$1.8 \mathrm{~mm}$. The characters of the mature larva are now first seen. Body black, the processes of row $i$ with a short shaft on joints 4-12 and close set branches, each tipped with a short, black bristle or a long, pale seta. The branches are brownish yellow, contrasting with the body. The other processes have a long, thick shaft and separated branches as all did in the previous stage. Rather scant, pale hairs arise from the skin.

Stage IV.-Much as in the next stage, but darker, more shining, the body less hairy, and without any distinct lines. Width of head 2.2-3.3 $\mathrm{mm}$.

Stage V.-Head rounded, median suture deep in front, clypeal sutures double; many coarse pale hairs. Color shining black, shaded with dull crimson on clypeus; width $3 \cdot 7-4.5 \mathrm{~mm}$. Processes arranged as follows : row $\mathrm{i}$ subdorsal on joints 2-rI, a single dorsal one on joints 12 and 13 , none on anal 
plate; row ii lateral, on joints 2-I3; row iii substigmatal on joints 2-13; row iv above bases of legs on joints 2-4 and correspondingly on joints 5, 6, I 1 and $\mathrm{I} 3$ anteriorly. There are three forms of the processes. The first, rosette-like, has a very short shaft with some 50 light brown quills with short black tips, which probably produce the strong urticating effect, besides a few central black branches which bear long terminal hairs. This type is found in row $i$ on joints 4- 12 . The second is intermediate. The shaft is long with brown quills arranged around the base and some ro black spines with terminal hairs, branching irregularly from the shaft and usually forming a trifid or bifid apex. This type is found in row $i$ on joints 2,3 and 13 and in row ii on joints $2-13$. In the third form there are no quills, the long shaft furnished with irregularly distributed, subradiate branches tipped by long hairs. The branches are black; but many are partly or wholly light brown. This type is found in rows iii and iv. Three shining black, irregularly indented, hairy anal plates and a large rounded quadrangular cervical shield, bearing the processes of rows $\mathrm{i}$ and $\mathrm{ii}$ on joint 2. Body black with faint subdorsal and lateral and broader substigmatal, sinuate lilac lines, or nearly immaculate. Hair from the skin white, not long, but quite abundant, giving a grayish appearance to the larva.
Spiracles reddish white with a black line centrally. Claspers of abdominal feet tinged with dull crimson.

Cocoon.-Very slight, composed of a few threads drawing together loose material or, more commonly, none. The larvae conceal themselves, but do not enter the earth.

Pupa.-Rounded conical, thickest through the thorax, tapering posteriorly. Cases large and prominent, but very even and closely packed. Anterior end rounded; posterior end also rounded, much smaller. Segmental incisures abrupt, not deep, with little capability of motion. Cremaster reduced to a bunch of short hairs on a slight prominence, colored red-brown, curving outward. Surface finely granular. Color dark mahogony red, the cases a little paler. Length 25 $\mathrm{mm}$; width through thorax $9 \mathrm{~mm}$., through abdomen at second moveable incisure $7 \mathrm{~mm}$. Four incisures are well marked; but the posterior one is scarcely moveable, being coarsely punctured, while the others are smooth. Imago in about 50 days after pupation.

Fcod plants.-Wild lilac (Ceanothus), Manzanita (Arctostaphylos), etc. Fed in confinement on cultivated cherry.

Larvae from Watsonville, California. Others seen, but not bred, at Yosemite and Monterey, Cal. and Portland, Oregon. The larvae are gregarious till quite large.

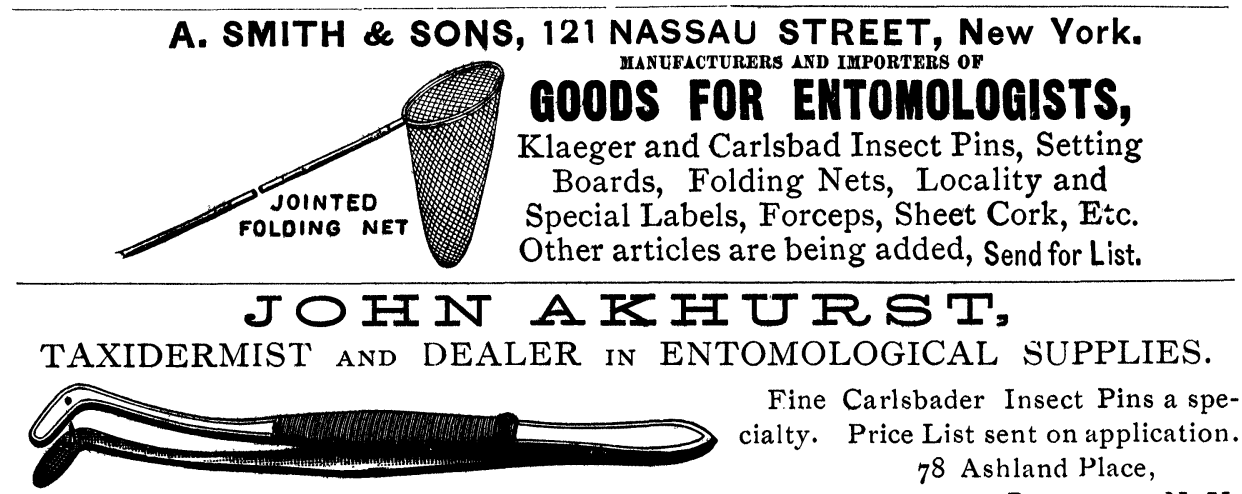

IMPROVED ENTOMOLOGICAL FORCEPS. 



Submit your manuscripts at

http://www.hindawi.com
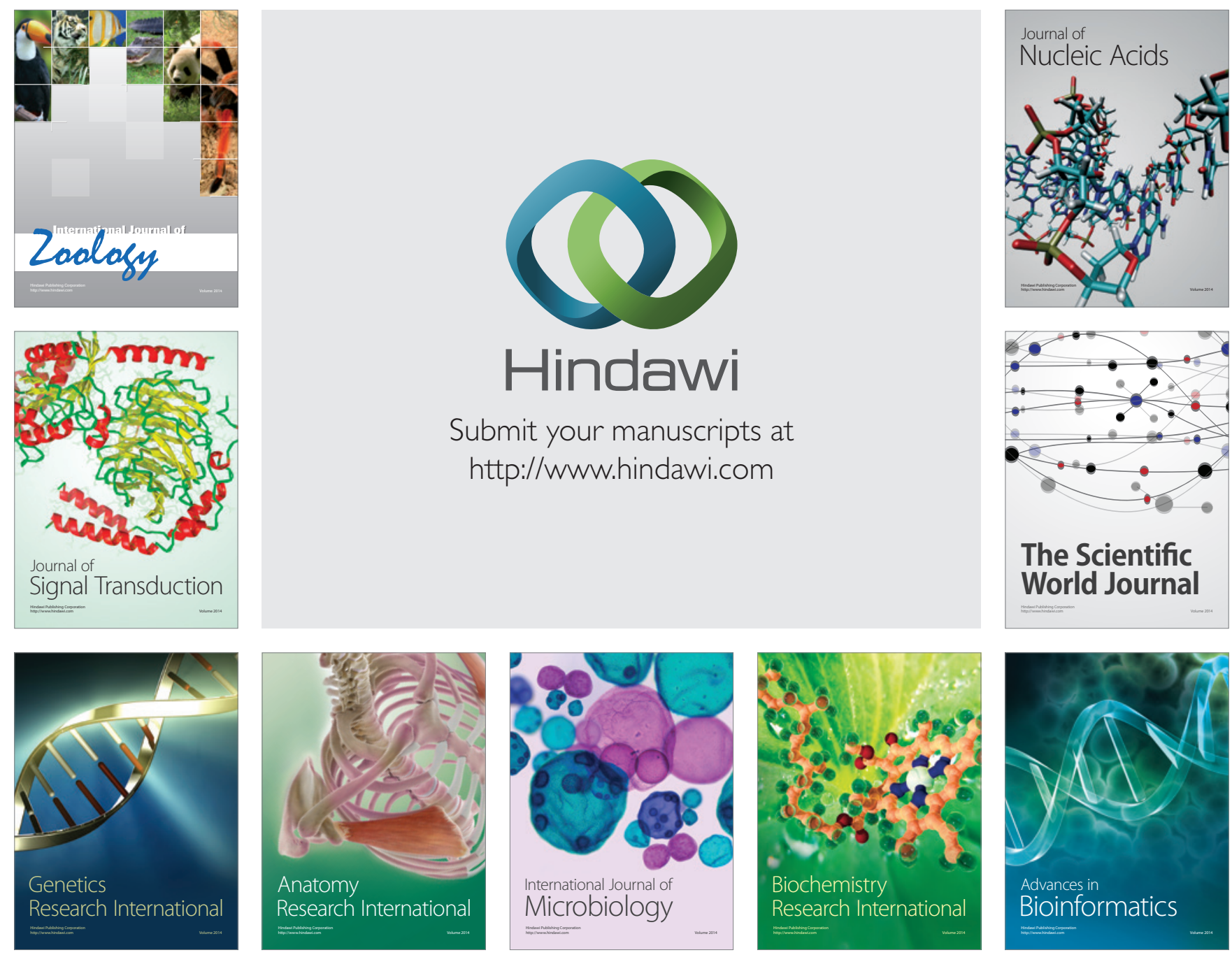

The Scientific World Journal
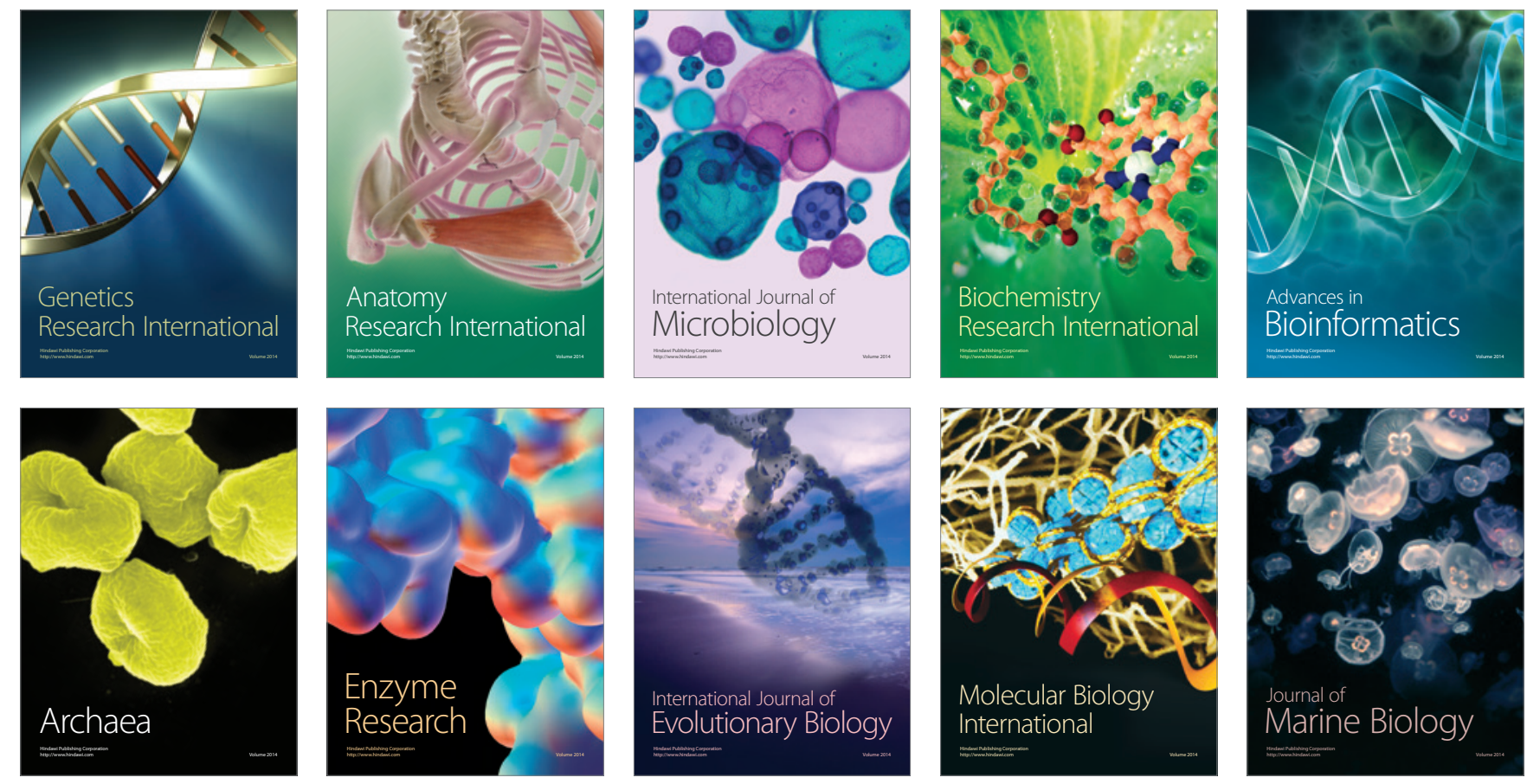